\title{
A Novel External Fixator to Facilitate Accurate and Efficient Fracture Treatment
}

\section{Mingkui Shen}

Southern University of Science and Technology

\section{Lulu Wang}

Southern University of Science and Technology

\section{Zizheng Ai}

Jiangxi University of Traditional Chinese Medicine

Jingna Li

Jiangxi University of Traditional Chinese Medicine

Huaping Liang

Army Medical University

Xieping Dong ( $\nabla$ xpdongdocteor@163.com )

Jiangxi Provincial People's Hospital

\section{Research article}

Keywords: External fixator, Fracture, Cadaver femur fracture, Biomechanics

Posted Date: January 18th, 2021

DOI: https://doi.org/10.21203/rs.3.rs-146655/v1

License: (c) (1) This work is licensed under a Creative Commons Attribution 4.0 International License. Read Full License 


\section{Abstract}

Background: The rapid popularization and application of bone external fixation technology has led to external fixators emerging as remarkable methods to treat various complex fractures. Because of their instability, assembly complexity and poor controllability, however, new external fixators are challenging to design in terms of facilitating accurate and efficient fracture treatment.

Methods: We designed a novel external fixator that could feasibly treat clinical complex fractures. A prospective study was conducted on patients with various complex fractures from September 2017 to September 2019. During this period, we treated 24 patients with a universal joint external fixator and then evaluated its therapeutic effects. In this study, adult cadaver femur fracture fixations were modelled by using universal joint (UJ) and $\mathrm{AO}$ external fixators, and the mechanical stability was assessed by applying a biomechanical testing device.

Results: The designed device not only fits the repair site but could also be conveniently installed and implanted. All patients achieved good fixation and fracture healing with the universal joint fracture external fixators. In in vitro biomechanical testing, constructs were loaded under axial compression, lateral compression and torsion. Overall axial stiffness showed no significant differences between the two groups. The lateral stiffness was $1.554 \pm 0.017 \mathrm{~mm}$ for the UJ group and $1.342 \pm 0.020 \mathrm{~mm}$ for the AO group ( $p<0.001)$ under a $600 \mathrm{~N}$ load, while the torsional stiffness was $15.727 \pm 0.141^{\circ}$ for the UJ group and $14.472 \pm 0.292^{\circ}$ for the $\mathrm{AO}$ group under a $40 \mathrm{Nm}$ load.

Conclusion: In this small and preliminary study, the universal joint external fixator, which achieved a stable mechanical structure, was capable of intensive and efficient treatment for comprehensive fractures. If these findings can be confirmed in a larger study, this external fixator may be widely used in certain situations where traditional external fixators are not a convenient option.

\section{Introduction}

External fixation systems are widely used for treating fractures. There are many commonly accepted indications for the application of an external fixator, such as open fractures that require continuous debridement, soft tissue coverage and eventual stable internal fixation[1]. Furthermore, there are many types of external bone fixators applied to the fracture healing process despite their numerous disadvantages, which include potential nail infection, instability, assembly complexity and poor controllability $[2,3]$. At the scene of a disaster, there may be many casualties with complicated conditions, and it is necessary to quickly fix any fractures and effectively reduce bleeding to reduce patients' pain and create conditions for further treatment. The unilateral Bastiani external fixator is widely used but suffers from complex operation, the need for image-assisted equipment and instability[4]. Hence, it is not suitable for application in emergency treatment, such as scenes of mass accidents. For open fractures with extensive soft tissue injury, the "reduction-first" type of external fixator is often difficult to apply due to the lack of safe nail channels[5]. Meanwhile, the existing "nail-priority" external fixator has a 
complicated combination structure and requires many components that need to be connected to achieve a stable structure, and there are no specific rules for the combination and consumption of the parts[6, 7]. The use of external fixators thus places high requirements on the distribution of the product and the technical level of the surgeon, and conventional external fixators are difficult to apply at injury scenes, for patient transfers and in conditions where no image assistance is possible.

Accordingly, designing a targeted external fixator has become a critical issue. For patients with severe trauma fractures, an external fixator is used for temporary fixation to treat the fracture. Not only is the operation simple, convenient and fast, but it can also give the patient a specific recovery time, allowing the surgeon to choose the appropriate date to perform the planned operation and repair the non-fatal wound. In the present study, we designed a novel external fixator for facilitating fracture treatment that is more applicable to various environments. Treating fracture patients, we assessed the clinical efficacy and validated the mechanical stability of our universal joint external fixator.

\section{Materials And Methods}

\section{External Fixator Designs}

Application To overcome the shortcomings of existing external fixators, which cannot be well adapted to controlled fixation of accident victims' injury sites, we invented a novel external fixator that not only conveniently performs damage-controlled fixation of various complex fractures but also applies the original external fixator to secondary restoration, performing the nail channel's non-invasive changes when the patients' general condition and medical conditions permit.

Technical Scheme a) The external fixator is designed as a single-arm external fixator with few components, which is convenient for distribution, disinfection and transportation. b) The fixation method is designed to be a multiplanar fixation that prioritizes nail penetration and increases fixation strength. $\mathbf{c}$ ) Between both ends of the fracture, a connection is designed that can be greatly deformed in all directions and is sufficiently flexible to allow nail penetration and noninvasive secondary reduction and fixation.

Instrument Structure We used Mimics 19.0 software to design a universal joint fracture external fixator based on a three-dimensional model and nailing plan (Fig. 1). This novel device is composed of brackets, nail lockers and fixed nails. The brackets are composed of a distal bracket, a proximal bracket and a coupler. The distal bracket and the proximal bracket are the main frames of the external fixator and are used as the attachment brackets for the nails and nail lockers for the distal and proximal fractures, respectively. The coupler, which is a fastening universal bonder, connects the distal and proximal brackets together. When the coupler is loose, the distal and proximal brackets can be relatively closed, shifted, angled and twisted. When the coupler is tightened, the device becomes a rigid fixator.

\section{Patient Inclusion Criteria}


After receiving approval from Jiangxi Provincial People's Hospital Affiliated to Nanchang University, patients who suffered from various traumas complicated with fracture were considered as the research objects in a prospective trial, which took place in the hospital from September 2017 to September 2019. Based on the willingness of the patients and their guardians to be treated with UJ external fixators, 24 patients were included in this study. We evaluated the clinical efficacy of the UJ external fixators in terms of the practicality of disease and related complications. The radiographs were analysed pre-fixation, postfixation and at the final follow-up.

\section{Biomechanical Testing}

After receiving approval from Jiangxi Provincial People's Hospital Affiliated to Nanchang University, we generated 10 approximate adult cadaver femur fracture models (Figure S1), which were divided into two groups according to external fixators: the UJ group $(n=5)$ and the AO group $(n=5)$. The two groups were then tested non-destructively by using a CTM2200 microcomputer-controlled electronic universal testing machine, a Zwick (B22.5/TSIS, Germany) material testing machine and a $100 \mathrm{~N} \mathrm{~m}$ microcomputercontrolled torsion testing machine to determine axial, lateral and torsional stiffness (Fig. 2). For axial and lateral compression, a maximum load of $600 \mathrm{~N}$ was applied at respective loading speeds of $20 \mathrm{~N} / \mathrm{s}$ and $50 \mathrm{~N} / \mathrm{s}$ with a preload of $200 \mathrm{~N}$, and then we measured the displacement of the specimens. For torsion, a maximum load of $40 \mathrm{~N} \mathrm{~m}$ was applied at a rotational speed of $0.3^{\circ} / \mathrm{s}$, and then we measured the rotation angle.

\section{Statistical Analysis}

Data are presented as the mean \pm standard deviation using IBM SPSS Statistics v.21.0 (IBM Corp., Armonk, N.Y., USA). If the collected data were distributed normally and with homogeneity of variance, independent sample t tests were used to determine any significant differences between the groups. If not, the Kruskal-Wallis rank sum-test was used. A p-value $<0.05$ was considered statistically significant.

\section{Results}

\section{Advantages of the UJ External Fixator}

First, the UJ external fixator is a versatile device that prioritized nail penetration and is capable of singlearm multi-dimensional fixation (Fig. 1A). It can avoid the wound surface and connect the bone nails in multiple dimensions to form a strong multi-planar fixation. A single-arm fixator can fix nails around approximately $2 / 3$ the diameter of the bone. Second, it noninvasively corrects reduction by utilizing UJ external fixators (Fig. 1B and C). The number of components did not increase nor did the position of the nails change when we needed to correct fracture reductions. Third, compared with traditional external fixators, the UJ external fixator consists of fewer components, which are easier to carry and assemble, and delivers more power. Given that it can be flexibly adjusted, the UJ external fixator could be used for pelvic fractures, limb fractures and ankle fractures, among others.

\section{Clinical application}


Twenty-four patients with different fracture types were finally included in this study. All patients were followed up for an average of 23.7 months ( $21 \rrbracket 36$ months). There were 17 males and 7 females, and the age ranged from 7 to 60 years old. Patients who were treated in trauma scenes or in the hospital were evaluated at the time of placing the UJ external fixator to assess the effect of damage-controlled fixation, fracture fixation and complications. Through radiographic observation, we assessed the patients' fracture fixation status as well as the condition of the fracture healing. During the treatment, the UJ external fixator was fixed firmly without nail loosening and displacement. The fracture patients healed well during follow-up. There were no intraoperative or postoperative complications, including infection, delayed union or breakage of UJ external fixators. A clinical case analysis of the use of an UJ external fixator for a pelvic fracture is shown in Fig. 3.

\section{In Vitro Testing}

Given the experimental reliability, there were no between-group difference in terms of nail distance or nail insertion angle in the sagittal, coronal and horizontal planes (Tables S1-S4). For axial compression, Table I shows that no significant differences were detected between the two groups for loads of $100 \mathrm{~N}, 200 \mathrm{~N}$, $400 \mathrm{~N}$ and $600 \mathrm{~N}$. For lateral compression, Table II shows that there were no significant differences for loads of $100 \mathrm{~N}, 200 \mathrm{~N}$ and $400 \mathrm{~N}$. However, the UJ group exhibited poorer stiffness with a load of $600 \mathrm{~N}$ (equivalent to the weight of an average adult) than the AO group $(p<0.001)$. For torsion, Table III demonstrates that the UJ external fixator was likely to twist when the load exceeded $40 \mathrm{~N} \mathrm{~m}$.

\section{Discussion}

The external skeletal fixation technique is a minimally invasive operation in which nails are percutaneously implanted and connected with external frames. The stress transmitted between nails stimulates the regeneration and reconstruction of bone tissue[8]. Previous studies have justified the benefits of an external fixator in the treatment of fractures, as it can (1) maintain fracture stability by resisting rotation, shearing and varus-valgus forces $[9,10]$; (2) alleviate articular surface stress for articular fractures, thus protecting the articular surface[11]; and (3) supply a suitable environment for soft tissue and muscle recovery[12]. At present, external fixators are rarely used in trauma scenes, especially in field medical treatment. Hybrid external fixators have relatively more functions, but a large number of components must be used to meet the needs of different types of fractures[6, 13]. In addition, when an external fixator is attached to a joint, it will affect joint movement to some extent. Joint stiffness is a welldocumented complication during treatment external fixators, even resulting in heterotopic ossification[13-16].

In this study, we designed a novel external fixator that aims to overcome the shortcomings of existing external fixators that cannot be well adapted to control the fixation of an accident victim's injury site. The new external fixator is not only convenient for performing damage-controlled fixation of various complex fractures but can also be flexibly adjusted. The UJ external fixator is an intensive device that has a number of advantages over traditional external fixators. Several of these are listed as follows. 
1. Convenient delivery. The new fixator is small and requires no extra components.

2. Easy learning. The only tools required are an electric drill, a wrench and a nailer; junior physicians can manipulate the external fixator quickly.

3. Broad versatility. When applied to many kinds of fractures, the UJ external fixator can continue noninvasive controlled fixation to the final fixation.

4. No Sterilization. External fixators and tools can carry bacteria, but only the nails need to be sterilized, which makes the new fixator suitable for reuse in battle fields and disaster areas.

In our study, we observed a good fixation effect in which fracture patients healed well during follow-up according to radiographic observation. Because the UJ external fixator can be adjusted flexibly, joint deformity and stiffness can be avoided, and cross-joint fixation does not require pre-nail implantation after fixation. Therefore, the dynamic external fixator is a reliable and effective device for treating fractures, allowing early postoperative functional rehabilitation and restoring joint function. During the treatment, the UJ external fixator was fixed firmly without nail loosening and displacement. Moreover, there were no intraoperative or postoperative complications, including infection, delayed union or breakage of the UJ external fixators. Given that it supplies a suitable condition for fracture healing, the UJ external fixator achieved an acceptable treatment result.

Previous studies have confirmed that fixator stiffness is closely related to stability and fracture healing[17-19]. The overall stiffness of the fracture fixation device directly impacts the axial, torsional, and shear interfragmentary movement at the fracture site[20-22]. During axial and lateral biomechanical testing, we used a maximum load of $600 \mathrm{~N}$, which is similar to the weight of an average adult, to estimate the mechanical performance of the UJ external fixator. Our data suggest that the UJ external fixator exhibited biomechanical stability similar to that of $\mathrm{AO}$ external fixators, which indicates that the UJ external fixator conformed to clinical application standards. We found no significant differences in the stiffness of the rotational planes with a load below $40 \mathrm{~N} \mathrm{~m}$. This demonstrates that the UJ external fixator had a normal anti-torsion effect. Therefore, the UJ external fixator, with its good biomechanical stability, will lead to shear interfragmentary movement and promote fracture healing.

Some limitations should not be ignored. First, because the UJ external fixation technology was new to them, the patients and their guardians were fully informed of the purpose and the potential advantages and disadvantages of the device before surgery, as that was when we were able to communicate with them. Second, the relatively small sample size resulted in insufficient power for identifying significant differences, and a larger study will be performed to assess the mechanical stability.

\section{Conclusions}

In this small, preliminary study, we show that the UJ external fixator prioritizes nail penetration and possesses a flexible spatial structure to produce an intensive and efficient treatment for patient fractures. It can be noninvasively adjusted to ensure reduction of the fracture and can improve the operation skills of surgeons. In addition, the UJ external fixator has a stable mechanical structure. If these findings can be 
confirmed in a larger study, this external fixator may be widely used in certain situations where a traditional external fixator is not a convenient option.

\section{List Of Abbreviations}

UJ, Universal joint; AO, Arbeitsgemeinschaftfür Osteosynthesefragen.

\section{Declarations}

\section{Ethics approval and consent to participate}

This prospective study was approved by the Ethics Committee of Jiangxi Provincial People's Hospital Affiliated to Nanchang University. All participants included in this study were informed to use this novel external fixator based on their willingness and provided written informed consent. All methods were carried out in accordance with relevant guidelines and regulations.

\section{Consent to publication}

Not applicable.

\section{Availability of data and material}

This article is a clinical retrospective study, and the available data were collected from 24 patients. The biomechanical data of the external fixator specimens were provided by the Biomechanical Laboratory of Shanghai University. If someone wants to request the data from this study, he or she can contact Corresponding author (Xieping Dong, xpdongdoctor@163.com). at any time.

\section{Competing interests}

The authors declare that they have no competing interests.

\section{Funding}

Supported by the Open Fund of State Key Laboratory of Trauma, Burn and Combined Injury (No. SKLKF201710, No. 2013BAI05B00, and NO. 2013BBG70021).

\section{Authors' contributions}

MKS, HPL, and XPD contributed to conception and design. MKS, LLW, ZZA and JNL contributed to acquisition and analysis of data. MKS and LLW involved in drafting the manuscript. HPL and XPD revised this study critically for important intellectual content. All authors gave final approval of the version to be published. Corresponding author is XPD and HPL.

\section{Acknowledgements}


All the authors were directly involved in the whole process; therefore, we disclose that all the authors contributed equally to the research.

\section{References}

1. Tiziani S, Dienstknecht T, Osterhoff G, Hand TL, Teuben M, Werner CML, Pape HC: Standards for external fixation application: national survey under the auspices of the German Trauma Society. International orthopaedics 2019, 43(8):1779-1785.

2. Perrone GS, Leisk GG, Lo TJ, Moreau JE, Haas DS, Papenburg BJ, Golden EB, Partlow BP, Fox SE, Ibrahim AM et al: The use of silk-based devices for fracture fixation. Nature communications 2014, 5:3385.

3. Zhang J, Ebraheim N, Lause GE, Xiao B, Xu R: A comparison of absorbable screws and metallic plates in treating calcaneal fractures: a prospective randomized trial. The journal of trauma and acute care surgery 2012, 72(2):E106-110.

4. Marsh JL: Weekly pin-site care was as effective as daily care in patients with external fixation - WDahl A, Toksvig-Larsen S, Lindstrand A. No difference between daily and weekly pin site care: A randomized study of 50 patients with external fixation. Acta Orthop Scand. 2003 Dec;74 : 704-8. Commentary. Journal Of Bone And Joint Surgery-American Volume 2004, 86A(8):1835-1835.

5. Judet $\mathrm{H}$ : Five years of experience in hip navigation using a mini-invasive anterior approach. Orthopedics 2007, 30(10 Suppl):S141-143.

6. Abdel-Aal AM: llizarov bone transport for massive tibial bone defects. Orthopedics 2006, 29(1):70-74.

7. Saridis A, Panagiotopoulos E, Tyllianakis M, Matzaroglou C, Vandoros N, Lambiris E: The use of the llizarov method as a salvage procedure in infected nonunion of the distal femur with bone loss. The Journal of bone and joint surgery British volume 2006, 88(2):232-237.

8. Osagie-Clouard L, Kaufmann J, Blunn G, Coathup M, Pendegrass C, Meeson R, Briggs T, Moazen M: Biomechanics of two external fixator devices used in rat femoral fractures. Journal of orthopaedic research : official publication of the Orthopaedic Research Society 2019, 37(2):293-298.

9. Maniscalco P, Pizzoli AL, Renzi Brivio L, Caforio M: Hinged external fixation for complex fracturedislocation of the elbow in elderly people. Injury 2014, 45 Suppl 6:S53-57.

10. Yu JR, Throckmorton TW, Bauer RM, Watson JT, Weikert DR: Management of acute complex instability of the elbow with hinged external fixation. Journal of shoulder and elbow surgery 2007, 16(1):60-67.

11. Kodde IF, van Rijn J, van den Bekerom MP, Eygendaal D: Surgical treatment of post-traumatic elbow stiffness: a systematic review. Journal of shoulder and elbow surgery 2013, 22(4):574-580.

12. Wang W, Jiang SC, Liu S, Ruan HJ, Fan CY: Stability of severely stiff elbows after complete open release: treatment by ligament repair with suture anchors and hinged external fixator. Journal of shoulder and elbow surgery 2014, 23(10):1537-1544. 
13. Archdeacon MT, d'Heurle A, Nemeth N, Budde B: Is preoperative radiation therapy as effective as postoperative radiation therapy for heterotopic ossification prevention in acetabular fractures? Clinical orthopaedics and related research 2014, 472(11):3389-3394.

14. Charalambous CP, Morrey BF: Posttraumatic elbow stiffness. The Journal of bone and joint surgery American volume 2012, 94(15):1428-1437.

15. Myden C, Hildebrand K: Elbow joint contracture after traumatic injury. Journal of shoulder and elbow surgery 2011, 20(1):39-44.

16. Daum WJ, Scarborough MT, Gordon W, Jr., Uchida T: Heterotopic ossification and other perioperative complications of acetabular fractures. Journal of orthopaedic trauma 1992, 6(4):427-432.

17. Willie B, Adkins K, Zheng X, Simon U, Claes L: Mechanical characterization of external fixator stiffness for a rat femoral fracture model. Journal of orthopaedic research : official publication of the Orthopaedic Research Society 2009, 27(5):687-693.

18. Mark H, Nilsson A, Nannmark U, Rydevik B: Effects of fracture fixation stability on ossification in healing fractures. Clinical orthopaedics and related research 2004(419):245-250.

19. Mark H, Rydevik $B$ : Torsional stiffness in healing fractures: influence of ossification: an experimental study in rats. Acta orthopaedica 2005, 76(3):428-433.

20. Goodship AE, Kenwright J: The influence of induced micromovement upon the healing of experimental tibial fractures. The Journal of bone and joint surgery British volume 1985, 67(4):650655.

21. Claes LE, Heigele CA, Neidlinger-Wilke C, Kaspar D, Seidl W, Margevicius KJ, Augat P: Effects of mechanical factors on the fracture healing process. Clinical orthopaedics and related research 1998(355 Suppl):S132-147.

22. Moazen M, Jones AC, Leonidou A, Jin Z, Wilcox RK, Tsiridis E: Rigid versus flexible plate fixation for periprosthetic femoral fracture-computer modelling of a clinical case. Medical engineering \& physics 2012, 34(8):1041-1048.

\section{Tables}


Table I.

The Axial Loading Displacement Experiment

\begin{tabular}{|llll|}
\hline Load & UJ group Mean \pm SD & AO group Mean \pm SD & p value \\
\hline $100 \mathrm{~N}$ & $0.126 \pm 0.020 \mathrm{~mm}$ & $0.120 \pm 0.022 \mathrm{~mm}$ & 0.408 \\
\hline $200 \mathrm{~N}$ & $0.294 \pm 0.154 \mathrm{~mm}$ & $0.297 \pm 0.204 \mathrm{~mm}$ & 0.585 \\
\hline $400 \mathrm{~N}$ & $0.563 \pm 0.202 \mathrm{~mm}$ & $0.549 \pm 0.265 \mathrm{~mm}$ & 0.198 \\
\hline $600 \mathrm{~N}$ & $0.919 \pm 0.038 \mathrm{~mm}$ & $0.957 \pm 0.043 \mathrm{~mm}$ & 0.785 \\
\hline $\begin{array}{l}\text { UJ, Universal joint fracture external fixation device; AO, Arbeitsgemeinschaftfür Osteosynthesefragen } \\
\text { fracture external fixation device. }\end{array}$ & \\
\hline
\end{tabular}

Table II.

The Lateral Loading Displacement Experiment

\begin{tabular}{|lllc|}
\hline Load & UJ group Mean \pm SD & AO group Mean \pm SD & P value \\
\hline $100 \mathrm{~N}$ & $0.327 \pm 0.021 \mathrm{~mm}$ & $0.333 \pm 0.015 \mathrm{~mm}$ & 0.331 \\
\hline $200 \mathrm{~N}$ & $0.661 \pm 0.016 \mathrm{~mm}$ & $0.607 \pm 0.019 \mathrm{~mm}$ & 0.305 \\
\hline $400 \mathrm{~N}$ & $0.995 \pm 0.017 \mathrm{~mm}$ & $0.994 \pm 0.021 \mathrm{~mm}$ & 0.931 \\
\hline $600 \mathrm{~N}$ & $1.554 \pm 0.017 \mathrm{~mm}$ & $1.342 \pm 0.020 \mathrm{~mm}$ & $<0.001$ \\
\hline $\begin{array}{l}\text { UJ, Universal joint fracture external fixation device; AO, Arbeitsgemeinschaftfür Osteosynthesefragen } \\
\text { fracture external fixation device. }\end{array}$ & \\
\hline
\end{tabular}

Table III.

The Torsional Loading Experiment

\begin{tabular}{|llll|}
\hline Load & UJ group Mean \pm SD & AO group Mean \pm SD & p value \\
\hline $10 \mathrm{~N} \mathrm{~m}$ & $2.027 \pm 0.160^{\circ}$ & $2.094 \pm 0.111^{\circ}$ & 0.632 \\
\hline $20 \mathrm{~N} \mathrm{~m}$ & $5.483 \pm 0.104^{\circ}$ & $5.550 \pm 0.115^{\circ}$ & 0.077 \\
\hline $30 \mathrm{~N} \mathrm{~m}$ & $9.200 \pm 0.119^{\circ}$ & $9.177 \pm 0.094^{\circ}$ & 0.583 \\
\hline $40 \mathrm{~N} \mathrm{~m}$ & $15.727 \pm 0.141^{\circ}$ & $14.472 \pm 0.292^{\circ}$ & $<0.001$ \\
\hline $\begin{array}{l}\text { UJ, Universal joint fracture external fixation device; AO, Arbeitsgemeinschaftfür Osteosynthesefragen } \\
\text { fracture external fixation device. }\end{array}$ & \\
\hline
\end{tabular}

\section{Figures}




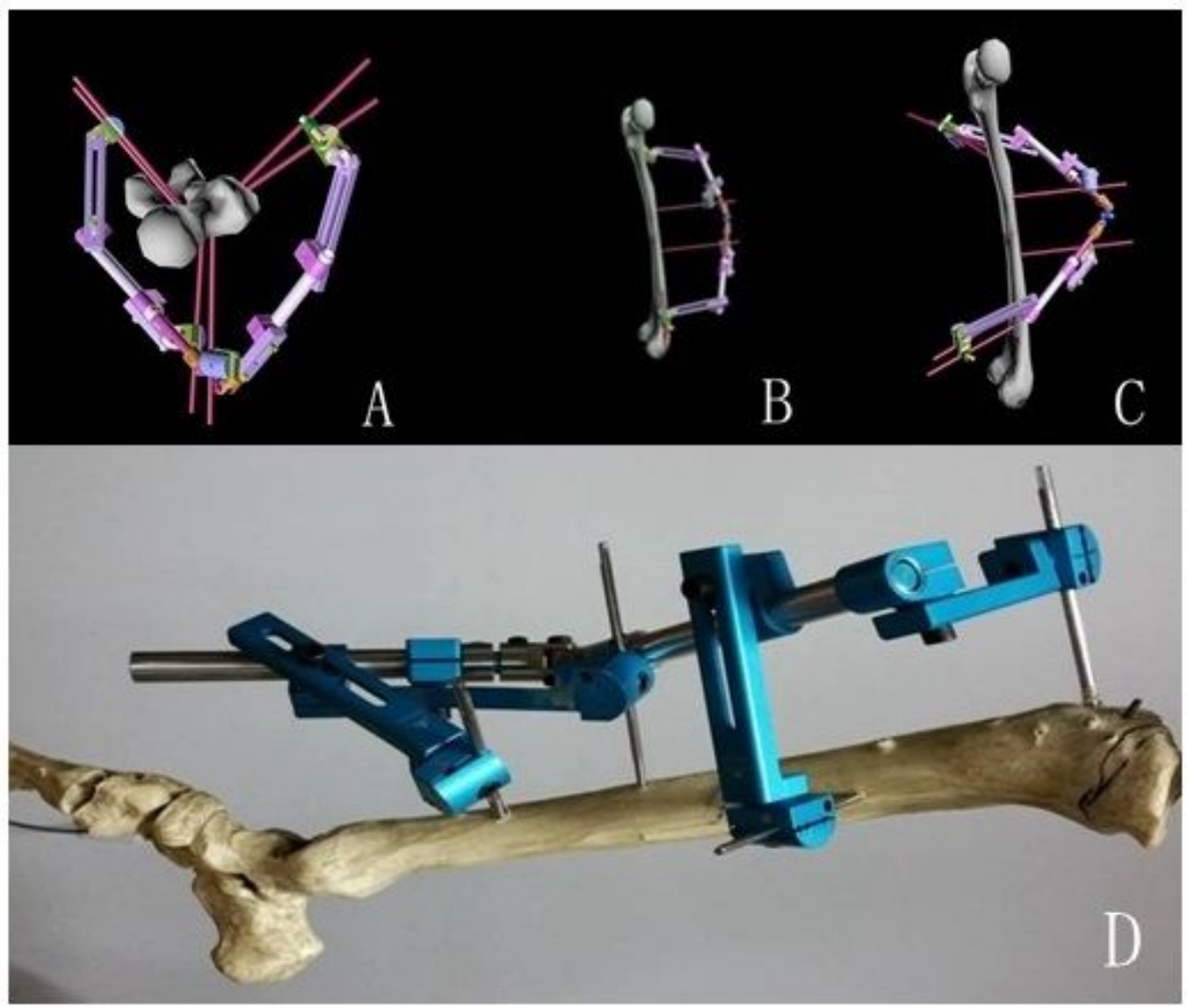

Figure 1

A schematic diagram of external fixator designs. $(A-C)$ Computer aided designs of the external fixator model. (D) Application of the external fixator in a tibial specimen. 


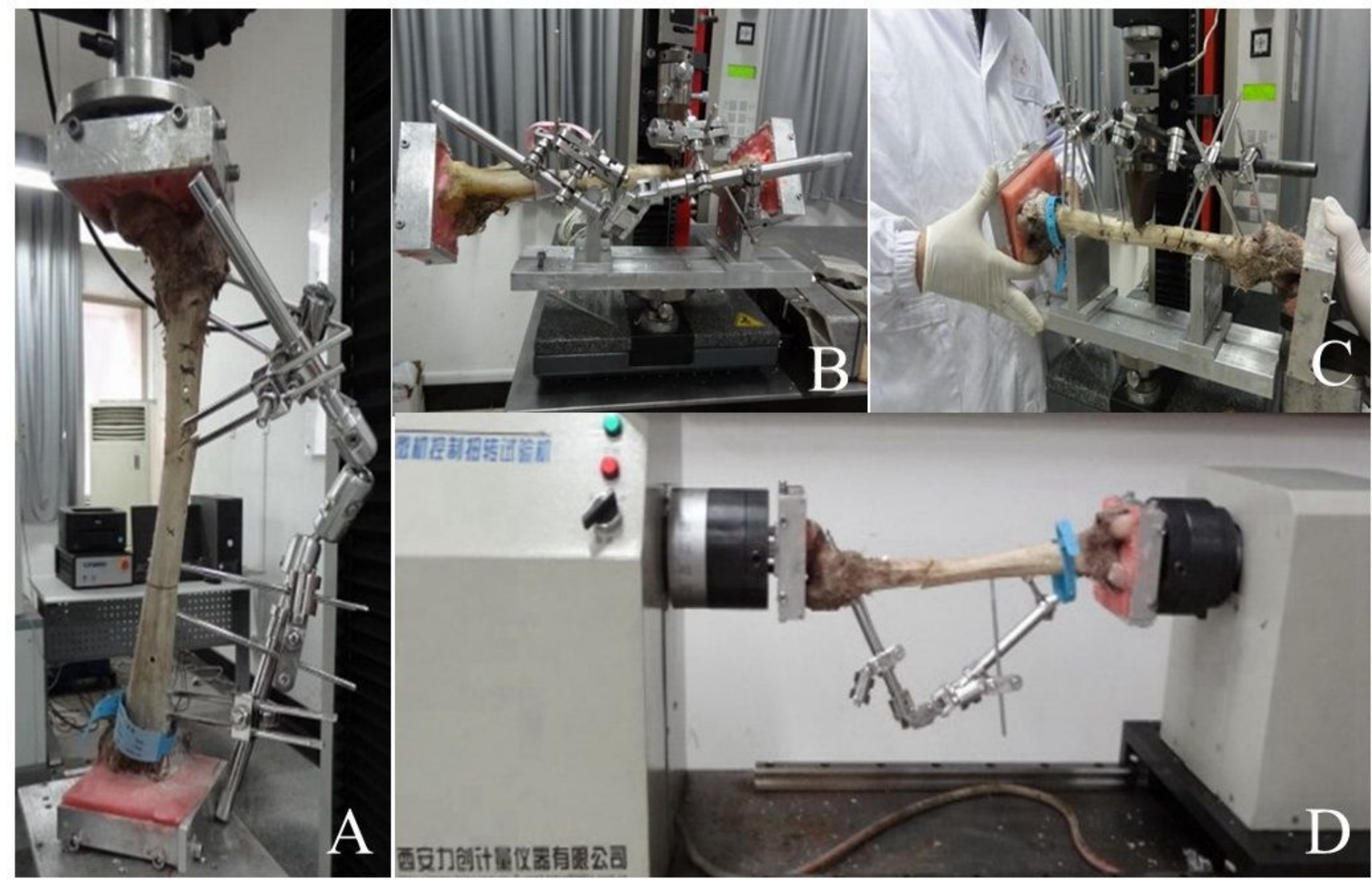

Figure 2

The mechanical stability of universal joint and $A O$ fracture external fixation device. (A) The axial loading displacement experiment. (B and C) The lateral loading displacement experiment. (D) The torsional loading experiment. 


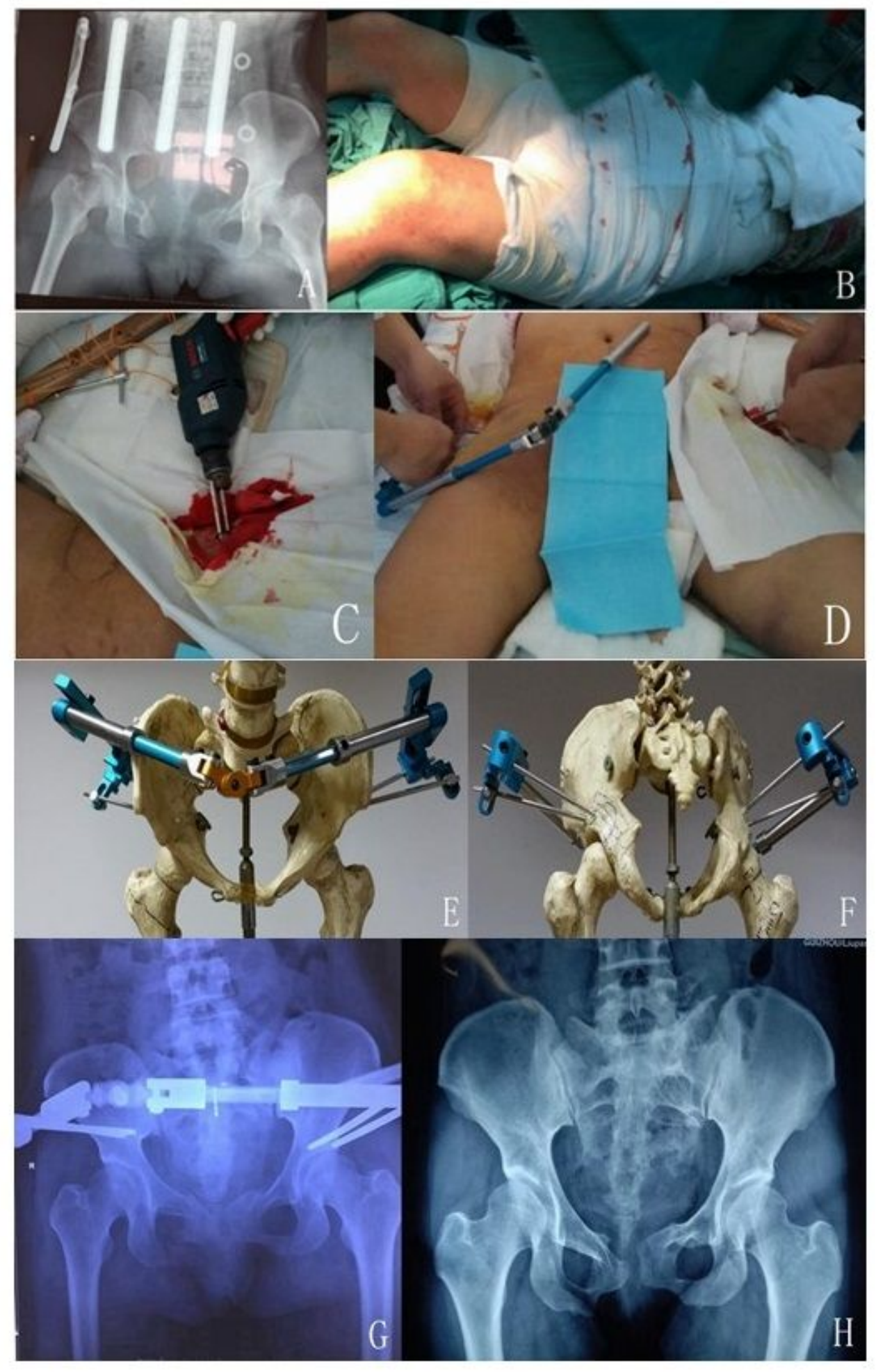

\section{Figure 3}

A 31-year-old female was brought to our emergency department by ambulance after sustaining trauma in a road traffic accident with poor vital signs (BP, 57/22 $\mathrm{mmHg}$ ). On examination, the pelvic compression test was positive. Plain radiograph showed that the displacement fracture of the pubic symphysis was not reset with the waist or girdle ( $A$ and $B$ ). In the supine position, bilateral iliac fixations were performed followed by application of the universal joint external fixator without imaging assistance (C and D). 
Demonstration of human pelvic specimen with the universal joint external fixator ( $E$ and $F$ ). After fixation, plain radiograph shows that the anterior pelvic ring was well closed $(G)$. A 28-month follow-up radiograph shows the pelvic fracture healing well with the universal joint external fixator for the final fixation treatment $(H)$.

\section{Supplementary Files}

This is a list of supplementary files associated with this preprint. Click to download.

- supplementarymaterials.docx 